\title{
Effect of Galvanic Skin Resistance-Aided Biofeedback Training in Reducing the Pulse Rate, Respiratory Rate, and Blood Pressure Due to Perceived Stress in Physiotherapy Students
}

\author{
Tushar J. PALEKAR ${ }^{1}$, Madhav G. MOKASHI', Shahnawaz ANWER ${ }^{1,2}$, Arjun L. KAKRANI ${ }^{3}$, Shilpa D. KHANDARE ${ }^{1}$, Ahmad H. ALGHADIR \\ ${ }^{1}$ Dr. D. Y. Patil College of Physiotherapy, Dr. D. Y. Patil Vidyapeeth Pimpri, Pune, MH, India \\ ${ }^{2}$ Rehabilitation Research Chair, College of Applied Medical Sciences, King Saud University, Riyadh, Saudi Arabia \\ ${ }^{3}$ Dr. D. Y. Patil Medical College and Hospital, Dr. D. Y. Patil Vidyapeeth, Pimpri, Pune, MH, India
}

\begin{abstract}
Objective: To investigate the effectiveness of galvanic skin resistance-aided biofeedback (GSRBF) training in reducing the pulse rate, respiratory rate, and blood pressure (BP) due to perceived stress in physiotherapy students.

Material and Methods: Forty-three students, those having a perceived stress scale (PSS) score of 20 or more out of 40, were subjected to GSRBF training 5 days a week for 3 weeks. The outcome measures of this study were pulse rate, respiratory rate, BP, and perceived stress. Perceived stress was assessed using PSS 10. Paired t-test was used to study the changes in dependent variables over time.

Results: The reduction of the pulse rate, respiratory rate, $\mathrm{BP}$, and perceived stress was found to be statistically significant at the end of the trial $(\mathrm{p}<0.001)$.

Conclusion: The GSRBF training was found to produce a significant reduction in the physiological response and perceived stress in physiotherapy students. Further, controlled research should be conducted to verify these findings and to identify the most effective stress-reducing training protocol.

Keywords: Perceived stress, galvanic skin response, biofeedback, relaxation
\end{abstract}

\section{Introduction}

The prevalence of stress during professional courses is significantly higher, which is increasingly being reported in recently published articles $(1,2)$. The incidence of distress such as the symptoms of depression is found to be high $(3,4)$, leading to an increased tendency to commit suicide $(5,6)$. The performance of students in the classroom as well as in clinical practice is greatly affected in the presence of emotional distress, leading to stressrelated disorders $(7,8)$. The presence of current mental distress and further health problems can be observed in those who perceive medical stress $(9,10)$.

The curriculum of the physiotherapy course has become vast in the present decade. The student's efforts are high to complete the course demands. Various future perspective needs such as securing a masters seat and being a competent clinical

Address for Correspondence: Shahnawaz Anwer, MPT, Rehabilitation Research Chair, College of Applied Medical Sciences, King Saud University, Riyadh, Saudi Arabia. Phone: +96614696012 E-mail: anwer_shahnawazphysio@rediffmail.com

Received: December 2013 Accepted: June 2014

OCopyright 2015 by Turkish Society of Physical Medicine and Rehabilitation - Available online at www.ftrdergisi.con

Cite this article as:

Palekar T], Mokashi MG, Anwer S, Kakrani AL, Alghadir AH. Effect of Galvanic Skin Resistance Aided Biofeedback Training in Reducing Pulse Rate, Respiratory Rate and Blood Pressure Due to Perceived Stress in Physiotherapy 
practitioner as well as other needs such as social and emotional factors influence the students' mental health. Hence, the students undergoing this course are predisposed to stress.

Recently, a variety of relaxation techniques have been introduced to reduce stress and anxiety, out of which biofeedback, (BF) training is found to be an effective tool in a variety of health conditions, ranging from hypertension to epilepsy (11). BF training enables the subject to control his body responses such as heart rate. Paran et al. (12) have found an improvement in blood pressure (BP) and a reduction in medication after the intervention of biofeedback-assisted relaxation training. Mogra and Singh have reported a reduction in systolic and diastolic BP after the intervention of yogic relaxation in combination with galvanic skin resistance-aided biofeedback (GSRBF) training of 30 min over a period of 2 months (13).

The purpose of the present study was to investigate the effectiveness of GSRBF training in reducing the pulse rate, respiratory rate, $\mathrm{BP}$, and perceived stress in physiotherapy students.

\section{Material and Methods}

\section{Setting and Participants}

The present study was undertaken at Dr. D. Y. Patil Physiotherapy College, Pune. The students of the second, third, and fourth year of the Bachelor's in Physiotherapy (BPT) course were invited to participate in this study. The subjects having a perceived stress scale (PSS) score of 20 or more were included in the study.

\section{Procedure}

The design of this study was a pretest-posttest quasi-experimental study. This study has the approval of the Sub-ethics committee, Research Cell of Dr. D. Y. Patil Physiotherapy College, Pune. A total of 71 physiotherapy undergraduate students were invited to participate in this study. The outcome measures of this study were the pulse rate, respiratory rate, BP, and perceived stress. A total of 43 subjects having a PSS score of 20 or more underwent GSRBF training 5 days a week for 3 weeks. Informed written consent for participating in the study was taken from all the subjects. All experiments were conducted according to the Declaration of Helsinki.

Assessment of Clinical Parameters and Perceived Stress

The subjects were made to assume a supine lying position. The pulse rate and BP was measured using an electronic digital BP apparatus (Omron - Automatic Blood Pressure Monitor; Model HEM - 7111). The respiratory rate was recorded by observing the movement of the chest wall for 1 min. Perceived stress was assessed using PSS 10. This scale is most widely used for measuring the perception of stress. PSS can be easily administered in community samples with junior of alteast high school education. The items and response alternatives could be understood and easy to grasp. The ques- tions asked in PSS are related to feelings and thoughts during the last month. In each case, the respondents are asked how often they felt a certain way repeatedly. This scale has been documented for its reliability and validity for measuring the perception of stress (14).

Galvanic Skin Resistance-Aided Biofeedback Training

The subject was made to sit comfortably on a chair, placed in front of a GSR machine (GSR Biofeedback "Biotrainer" GBF-2000, Medicaid systems). Before the electrode placement, the part to be treated was thoroughly cleaned with alcohol solution to reduce the skin resistance. The electrodes were fixed on the index and ring finger using a Velcro tape, and the subject was instructed to relax voluntarily using visual feedback from the machine. The training was provided for 10 min daily for 5 days a week for 3 weeks.

\section{Statistical Analysis}

Statistical analysis was performed using the Statistical Package for the Social Sciences (SPSS) 15.0 Software (SPSS Inc., Chicago, IL, USA). Shapiro-Wilk tests were completed to assess whether the dependent variables conformed to a normal distribution and whether parametric testing could be performed. The result of the Shapiro-Wilk tests suggested that the dependent variables were normally distributed ( $p>0.05)$. Thus, a parametric test was used to analyze the data. Paired t-test was used to study the changes in dependent variables over time. The level of statistical significance was $\mathrm{p}<0.05$.

\section{Results}

Of the 71 subjects who were assessed for perceived stress, 43 subjects (eight males, 35 females) had a PSS score of 20 or more and agreed to participate in the study. The subject's characteristics, including age, weight, height, and body mass index (BMI), were recorded (Table 1). The pulse rate, respiratory rate, $\mathrm{BP}$, and $\mathrm{PSS}$ score was compared between the baseline and at the end of the third week. Significantly lower values were noted in all the parameters $(p<0.001)$ (Table 2$)$. During the 3 -week training period, the mean (SD) reduction of the pulse rate, respiratory rate, systolic BP, diastolic BP, and PSS score was found to be 8.79 (5.37), 3.37 (2.90), 4.07 (4.05), 3.37 (4.40), and 8.00 (2.37), respectively.

Table 1. Subject characteristics

\begin{tabular}{lccc} 
& \multicolumn{3}{c}{ Range } \\
\cline { 3 - 4 } & Mean (SD) & Maximum & Minimum \\
\hline Age (years) & $19.30(2.98)$ & 18 & 22 \\
Weight $(\mathrm{kg})$ & $62.63(20.39)$ & 36 & 115 \\
Height $(\mathrm{m})$ & $1.56(0.07)$ & 1.45 & 1.79 \\
BMI $\left(\mathrm{kg} / \mathrm{m}^{2}\right)$ & $25.36(7.27)$ & 15.38 & 42.54
\end{tabular}

SD: standard deviation; BMI: body mass index 


\begin{tabular}{|c|c|c|c|c|c|c|}
\hline & $\begin{array}{c}\text { Baseline } \\
\text { Mean (SD) }\end{array}$ & $\begin{array}{c}\text { Week } 3 \\
\text { Mean (SD) }\end{array}$ & \multicolumn{2}{|c|}{ t-test } & \multicolumn{2}{|c|}{$\begin{array}{l}95 \% \text { Confidence interval } \\
\text { of the difference }\end{array}$} \\
\hline Pulse rate & $81.42(12.65)$ & $72.63(8.62)$ & 10.717 & 0.001 & 7.135 & 10.446 \\
\hline Respiratory rate & $20.12(3.66)$ & $16.74(1.70)$ & 7.616 & 0.001 & 2.479 & 4.266 \\
\hline Systolic BP & $116.21(7.43)$ & $112.14(5.57)$ & 6.590 & 0.001 & 2.823 & 5.316 \\
\hline Diastolic BP & $69.84(8.12)$ & $66.47(5.40)$ & 5.017 & 0.001 & 2.016 & 4.729 \\
\hline
\end{tabular}

PSS: Perceived Stress Score; BP: blood pressure; SD: standard deviation

\section{Discussion}

This study was designed to investigate the effect of GSRBF training in reducing the pulse rate, respiratory rate, $B P$, and perceived stress in physiotherapy students. The data showed that 3 weeks of GSRBF training led to a significant reduction in physiological responses and perceived stress.

Our results provide preliminary evidence that GSRBF training was associated with significantly lower values in physiological responses such as the pulse rate, respiratory rate, BP, and perceived stress. The findings in our study are consistent with a previous research, which reported the beneficial effect of GSRBF on these physiological responses and stress. Paran et al. (12) have reported an improvement in BP and a reduction in medication after the intervention of biofeedback-assisted relaxation training. Mogra and Singh (13) have reported lower values in systolic and diastolic $\mathrm{BP}$ after the intervention of yogic relaxation in combination with GSRBF training of 30 min over a period of 2 months.

Similarly, Khanna et al. (15) compared the three groups: (1) GSRBF group, (2) progressive muscle relaxation (PMR) training group, and (3) control group. They concluded that both the GSRBF and PMR groups significantly reduced the pulse rate and anxiety score over a period of 10 days. However, in their study, PMR training was found to be more effective than GSRBF training in reducing the pulse rate and anxiety scores.

Agnihotri et al. (16) investigated the effect of electromyographic (EMG) and electroencephalographic (EEG) BF relaxation trainings on generalized anxiety disorders. They reported that both EMG and EEG BF relaxation trainings resulted in a remarkable improvement in GSR and a significant decrease in state and trait anxiety after 12 days of treatment. In another study, Turankar et al. (17) reported a significant drop in the resting pulse rate following a week-long relaxation practice, irrespective of practicing pranayama.

The parameters measured can be affected by various factors such as the time at which measurement was taken, coffee or alcohol intake, meals, regular exercise, age, everyday life stress. To minimize these constrains, we measured all the parameters at the same time (morning), and the range of age group was kept constant (18-22 years). In addition, the subjects were instructed not to exercise. The limitation of the present study was that the long-term effect of the GSRBF training program was not assessed. The lack of a control group is the other limitation of this study. However, because of the variability in the subject's baseline characteristics such as heart rate, BP, and respiratory rate, it is difficult to form a homogenous group of control subjects.

\section{Conclusion}

Galvanic skin resistance-aided biofeedback training is found to produce a significant reduction in the pulse rate, respiratory rate, BP, and perceived stress in physiotherapy students. Further, controlled research should be conducted to verify these findings and to identify the most effective stress reducing training protocol.

Ethics Committee Approval: This study has approval of Sub-ethics committee, Research Cell of Dr. D. Y. Patil Physiotherapy College, Pune.

Informed Consent: Written informed consent was obtained from patients who participated in this study.

Peer-review: Externally peer-reviewed.

Author Contributions: Concept - T.J.P., M.G.M., A.L.K.; Design - T.J.P., M.G.M., S.A.; Supervision - M.G.M., A.L.K.; Resource - T.J.P., M.G.M., A.H.A.; Materials - T.J.P., S.A., S.D.K.; Data Collection and/or Processing - S.A., T.J.P., S.D.K.; Analysis and/or Interpretation - S.A., T.J.P., M.G.M., A.H.A.; Literature Review - T.J.P., S.A., S.D.K.; Writer - T.J.P., S.A.; Critical Review - All the authors critically reviewed and approved the final manuscript.

Acknowledgement: The Project was financially supported by king Saud University, through Vice Deanship of Research Chairs, Rehabilitation Research Chair.

Conflict of Interest: No conflict of interest was declared by the authors.

Financial Disclosure: King Saud University, through Vice Deanship of Research Chairs, Rehabilitation Research Chair supported financially to this study.

\section{References}

1. Aktekin $M$, Karaman $T$, Senol YY, Erdem S, Erengin $H$, Akaydin M. Anxiety, depression and stressful life events among medical students: a prospective study in Antalya, Turkey. Med Educ 2001;35:12-7. [CrossRef]

2. Guthrie EA, Black D, Bagalkote $H$, Shaw C, Campbell M, Creed F. Psychological Stress and Burnout in Medical Students: A Five-year Prospective Longitudinal Study. J R Soc Med 1998;91:237-43. 
3. Dahlin $\mathrm{M}$, Joneborg $\mathrm{N}$, Runeson $\mathrm{B}$. Stress and depression among medical students: a cross sectional study. Med Educ 2005;39:594604. [CrossRef]

4. Zocolillo M, Murphy GE, Wetzel RD. Depression among medical students. J Affect Disord 1986;11:91-6. [CrossRef]

5. Malathi A, Damodaran A. Stress due to exams in medical studentsrole of yoga. Indian J Physiol Pharmacol 1999;43:218-24.

6. Bramness JA, Fixdal TC, Vaglum P. Effect of medical school stress on the mental health of medical students in early and late clinical curriculum. Acta Psychiatr Scand 1991;84:340-5. [CrossRef]

7. Tyssen R, Vaghum P, Grønvold NT, Ekeberg O. Suicide ideation among medical students and youth physicians: a nationwide and prospective of prevalence and predictors. I Affect Disord 2001;64:69-79. [CrossRef]

8. Tyssen R, Hem E, Vaghum P, Grønvold NT, Ekeberg $\varnothing$. The process of suicidal planning among medical doctors: predictors in a longitudinal Norwegian sample. J Affect Disord 2004;80:191-8. [CrossRef]

9. Vitaliano PP, Russo J, Carr JE, Heerwagen JH. Medical school pressures and their relationship to anxiety. J Nerve Ment Dis 1984;172:730-6. [CrossRef]

10. Tyssen R, Vaglum P, Gronvold NT, Ekeberg O. Factors in medical scholl that predict postgraduate mental health problems in need of treatment. A nationwide and longitudinal study. Med Educ 2001;35:110-20. [CrossRef]

11. Bleecker ER, Engel BT. Learned control of cardiac function in Wolff Parkinson White syndrome. N Engl Med 2005;288:560-2. [CrossRef]

12. Paran E, Amir M, Yaniv N. Evaluation of the response of mild hypertensives to biofeedback assisted relaxation using mental stress test. J Behav Ther Exp Psychiatry 1996;27:157-67. [CrossRef]

13. Mogra AL, Singh G. Effect of biofeedback and yogic relaxation exercise on the blood pressure level of hypertensives: A preliminary study. Aviation Medicine 1986;30:68-75.

14. Cohen S, Kamarak T, Mermelstein R. A global measure of perceived stress. J Health Soc Behav 1983;24:385-96. [CrossRef]

15. Khanna A, Paul M, Sandhu JS. Efficacy of two relaxation techniques in reducing pulse rate among highly stressed females. Calicut Medical Journal 2007;5:e2.

16. Agnihotri $H$, Paul M, Sandhu JS. Biofeedback Approach in The Treatment of Generalized Anxiety Disorder. Iran J Psychiatry 2007;2:90-5.

17. Turankar AV, Jain $S$, Patel $S B$, Sinha $S R$, Joshi $A D$, Vallish $B N$, et al. Effects of slow breathing exercise on cardiovascular functions, pulmonary functions \& galvanic skin resistance in healthy human volunteers - a pilot study. Indian J Med Res 2013;137:916-21. 